\title{
Differential neuronal vulnerability varies according to specific cardiopulmonary bypass insult in a porcine survival model
}

\author{
Nobuyuki Ishibashi, MD, ${ }^{\mathrm{a}}$ Yusuke Iwata, MD, ${ }^{\mathrm{a}}$ Toru Okamura, MD, ${ }^{\mathrm{a}}$ David Zurakowski, PhD, \\ Hart G. W. Lidov, MD, ${ }^{c}$ and Richard A. Jonas, MD $^{\mathrm{a}}$
}

Objective: We investigated whether the degree of vulnerability of different areas in the developing brain varies according to the specific mechanism of the insults caused by cardiopulmonary bypass.

\begin{abstract}
Methods: A meta-analysis of 2 experimental studies $(n=80)$ was conducted. The end points of the otherwise identical studies were tissue oxygen index in the first experiment, whereas cerebral microvessel vasoconstriction and inflammatory response of endothelial cells were directly visualized in the second study. We assigned ultralow flow bypass at $25^{\circ} \mathrm{C}$ for 60 minutes as control; circulatory arrest at $25^{\circ} \mathrm{C}$ for 60 minutes as ischemic stress under circulatory arrest (ischemia-CA); and ultra-low flow bypass at $34^{\circ} \mathrm{C}$ for 60 minutes as the stress under ultra-low flow bypass (ischemia-ULF). Histologic neuronal damage was the primary outcome. Secondary measures included neurologic recovery.
\end{abstract}

Results: Vasoconstriction after ischemia and inflammation after bypass were independent predictors of severe histologic damage. The caudate nucleus was significantly vulnerable to ischemia-CA and was significantly influenced by vasoconstriction. In contrast, the hippocampus was significantly vulnerable to ischemia-ULF. The different forms of ischemic insults did not influence Purkinje cells, whereas Purkinje damage significantly correlated with inflammation. Tissue oxygen index had the ability to differentiate accurately regional damage. Neurologic recovery under ischemia-CA was significantly worse compared with ischemia-ULF. Neurologic recovery correlated with neuronal damage in the caudate nucleus, but it did not correlate with damage in the hippocampus.

Conclusions: Neuronal vulnerability in different areas of the developing brain varies according to mechanisms of bypass-induced ischemic stress. Certain regional damage may not be apparent in assessing acute neurologic recovery. (J Thorac Cardiovasc Surg 2010;140:1408-15)

Supplemental material is available online.

With more children surviving ever more complicated pediatric cardiac surgery, greater attention has been directed to the quality of life of survivors. One of the most important concerns is impaired neurologic development. ${ }^{1}$ The time course of brain development varies according to specific brain areas and types of cells. ${ }^{2}$ Although neurogenesis occurs mainly in utero, it also continues after birth, particularly in the hippocampus and olfactory bulb. ${ }^{3}$ In addition, synapse and myelin

From the Department of Cardiac Surgery, ${ }^{\text {a }}$ Children's National Medical Center, Washington, DC; and Departments of Surgery ${ }^{\mathrm{b}}$ and Pathology,${ }^{\mathrm{c}}$ Children's Hospital Boston, Boston, Mass.

This research was supported by National Institutes of Health Grant R01 HL060922. Disclosures: None.

Read at Fifth World Congress of Pediatric Cardiology and Cardiac Surgery, Cairns, Australia, June 21-26, 2009.

Received for publication Dec 30, 2009; revisions received Feb 12, 2010; accepted for publication March 12, 2010; available ahead of print May 3, 2010.

Address for reprints: Richard A. Jonas, MD, Department of Cardiac Surgery, Children's National Medical Center, 111 Michigan Ave, NW, Washington, DC, 20010-2970 (E-mail: rjonas@cnmc.org).

$0022-5223 / \$ 36.00$

Copyright $\odot 2010$ by The American Association for Thoracic Surgery doi:10.1016/j.jtcvs.2010.03.008 formation as well as development of glial cells proceed after birth with differences between regions. ${ }^{4}$ Furthermore, the expression of glutamate receptors such as $N$-methyl-D-aspartate receptors, which are of primary importance in excitatory neurotransmission and excitotoxic brain injury, also varies between brain regions and stage of development. ${ }^{5}$ Therefore, the response to ischemic stress may vary between regions and according to stage of development.

Brain energy metabolism during cardiopulmonary bypass (CPB) can be managed by control of temperature, flow rate, $\mathrm{pH}$ management, or hematocrit level. ${ }^{6,7}$ Oxygen consumption can be reduced by hypothermia or use of the $\mathrm{pH}$-stat strategy, and oxygen supply can be reduced through manipulation of flow rate, $\mathrm{pH}$, and hematocrit level. ${ }^{6,7} \mathrm{~A}$ mismatch of oxygen consumption and oxygen supply results in a patient being placed at risk of ischemic brain injury. During $\mathrm{CPB}$, children with congenital heart anomalies have an important risk of ischemic brain injury induced by energy mismatch; for example, cerebral ischemia can result from aortopulmonary collateral vessels that steal blood from the systemic to the pulmonary circulation. In addition to the variety of neural responses to ischemic stress, bypass-induced ischemic stress also varies according to many factors related to oxygen consumption and supply. The simultaneous complexity prevents us from 


$$
\begin{aligned}
& \text { Abbreviations and Acronyms } \\
& \begin{aligned}
\text { ANOVA } & =\text { analysis of variance } \\
\text { CPB } & =\text { cardiopulmonary bypass } \\
\text { FCD } & =\text { functional capillary density } \\
\text { NDS } & =\text { neuronal deficit score } \\
\text { OPC } & =\text { overall performance category } \\
\text { POD } & =\text { postoperative day } \\
\text { TOI } & =\text { tissue oxygen index }
\end{aligned}
\end{aligned}
$$

understanding the cellular level response of each area and type of cells under bypass environments. To investigate the neural response in various developing brain areas to various bypass-induced ischemic stress insults, we conducted a meta-analysis. Hence, the purposes of this study were (1) to understand how selective neuronal vulnerability in each area varies with different bypass stress, (2) to investigate the relation between regional neuronal damage and the cerebral microcirculation, (3) to assess accuracy of intraoperative monitoring in predicting different damage, and (4) to determine the correlation of acute neurologic recovery with regional histologic damage.

\section{METHODS}

\section{Animals}

We conducted a meta-analysis of 2 experimental studies. The 2 studies were performed using animals of the same age and size and same bypass settings. In the first study, tissue oxygen index (TOI) was measured by nearinfrared spectroscopy. ${ }^{8}$ In the second study, cerebral microcirculation was directly visualized by intravital microscopy. ${ }^{9}$ Eight animals in which vasoconstriction and inflammatory response were successfully measured were added in the second study for the meta-analysis $(\mathrm{n}=32)$. Of 54 animals in the first study, 48 animals that had the brain successfully fixed on postoperative day (POD) 4 were enrolled for the meta-analysis. ${ }^{8}$ A total of 80 Yorkshire piglets (aged $26.0 \pm 3.0$ days; weight $10.1 \pm 1.4 \mathrm{~kg}$ ) were enrolled for the meta-analysis (Figure E1).

Our previous laboratory studies demonstrated that ultra-low flow bypass $\left(10 \mathrm{~mL} \cdot \mathrm{kg}^{-1} \cdot \min ^{-1}\right)$ at $25^{\circ} \mathrm{C}$ for 60 minutes protects against histologic neuronal damage and places an individual in the safe zone with respect to ischemic injury during $\mathrm{CPB}^{7}$; in contrast circulatory arrest at $25^{\circ} \mathrm{C}$ and ultra-low flow at $34^{\circ} \mathrm{C}$ reliably cause histologic damage but secondary to different forms of ischemic stress. ${ }^{6,7}$ On the basis of these previous results from our studies with this model, we assigned ultra-low flow bypass at $25^{\circ} \mathrm{C}$ for 60 minutes as control (control group), circulatory arrest at $25{ }^{\circ} \mathrm{C}$ for 60 minutes as ischemic stress under circulatory arrest (ischemia-CA), and ultra-low flow bypass at $34{ }^{\circ} \mathrm{C}$ for 60 minutes as ischemic stress under ultra-low flow bypass (ischemia-ULF).

All animals received humane care in accordance with the "Principles of Laboratory Animal Care" formulated by the National Society for Medical Research and the "Guide for the Care and Use of Laboratory Animals," Two studies were approved by the Institutional Animal Care and Use Committee of the Children's National Medical Center.

\section{Surgery and CPB}

The 2 studies were performed using the same surgical methods and the same bypass strategy (Figure E1). The preparation and details of the methods have been described previously. ${ }^{8,9}$ All animals in the 2 studies were randomly infused with 1 of 4 doses of aprotinin (Trasylol; Bayer, West Haven, Conn): no aprotinin, low dose, standard full dose, and double full dose. ${ }^{8,9}$

\section{Cerebral Microcirculation}

A cranial window was created over the parietal cerebral cortex allowing direct visualization of the surface cerebral microvessels.

Microvessel vasoconstriction. The plasma was labeled with fluorescein-isothiocyanate-dextran $5 \%$ before each measurement. This allowed the assessment of functional capillary density (FCD), defined as total length of erythrocyte-perfused capillaries per observation area. Reduced endothelial function resulting from ischemic insults can be measured as reduced FCD secondary to vasoconstriction or "no-reflow."

Inflammatory response of endothelial cells. Postcapillary venules, 20- to 40- $\mu \mathrm{m}$ diameter, were observed for assessment of circulating leukocytes, which were labeled with $0.05 \mathrm{~mL} / \mathrm{kg}$ of rhodamine- $6 \mathrm{G} 0.2 \%$. Adherent leukocytes were defined as leukocytes that attached to the endothelium and did not detach within a 30 -second observation period. The number of adherent leukocytes was expressed per area over a $100-\mu \mathrm{m}$ length and $30-\mu \mathrm{m}$ diameter. Leukocyte adhesion is an indication of inflammatory response of the endothelial cells. ${ }^{10}$ Intravital fluorescence microscopy was performed until 3 hours after weaning from CPB (Figure E1). The details of the preparation and methods have been described previously. ${ }^{7,9,11}$

\section{TOI}

For assessment of brain tissue oxygenation during surgery, TOI was recorded using a near-infrared spectroscopy device (NIRO-300; Hamamatsu Photonics KK, Hamamatsu City, Japan) every 10 seconds after the induction of anesthesia and for 3 hours after weaning from CPB (Figure E1). ${ }^{6,8}$

\section{Histologic Analysis}

The brain was harvested on POD 4 (Figure E1). Histologic damage was scored using the following criteria: $5=$ all neurons necrotic; $4=$ significant damage to neurons; $3=$ large clusters of injured neurons; $2=$ small clusters of damaged neurons; $1=$ isolated neuronal damage; $0=$ normal. A single neuropathologist (H. G. W. L.) examined all specimens in a blinded fashion. ${ }^{6-9,11}$

\section{Neurologic Recovery}

Postoperative neurologic recovery was assessed on POD 1 and at 24-hour intervals up to POD 4 (Figure E1). Neurologic scoring data are adapted from the neuronal deficit score (NDS) and overall performance category (OPC) scale developed at the University of Pittsburgh and used extensively in our laboratory for pigs. ${ }^{6-9,11}$ In the modified NDS system, a score of 100 is assigned to each of 4 general components. A total score of 400 indicates brain death whereas a score of 0 is considered normal. The OPC score assesses outcome in 5 categories; $1=$ normal, $2=$ moderate disability, $3=$ severe disability, $4=$ coma, $5=$ brain death. The scores are assessed in a blinded fasion. ${ }^{8,9}$

\section{Statistical Analysis}

Continuous variables are expressed as mean \pm standard deviation. The Kolmogorov-Smirnov test of normality indicated that mean arterial pressure, esophageal temperature, arterial oxygen and carbon dioxide tension, $\mathrm{pH}$, hematocrit, and NDS followed a normal (Gaussian-shaped) distribution. Unpaired $t$ tests were used to compare FCD, adherent leukocyte numbers, and TOI between severities of histologic brain injury at a fixed time point. Physiologic variables were compared among the 3 experimental conditions by using 1 -way analysis of variance (ANOVA) with F tests. To assess effects of aprotinin, we used the $\chi^{2}$ test for comparing doses between experimental conditions, and we used the 2-way ANOVA to analyze the histologic damage scores to determine whether these scores were related to 

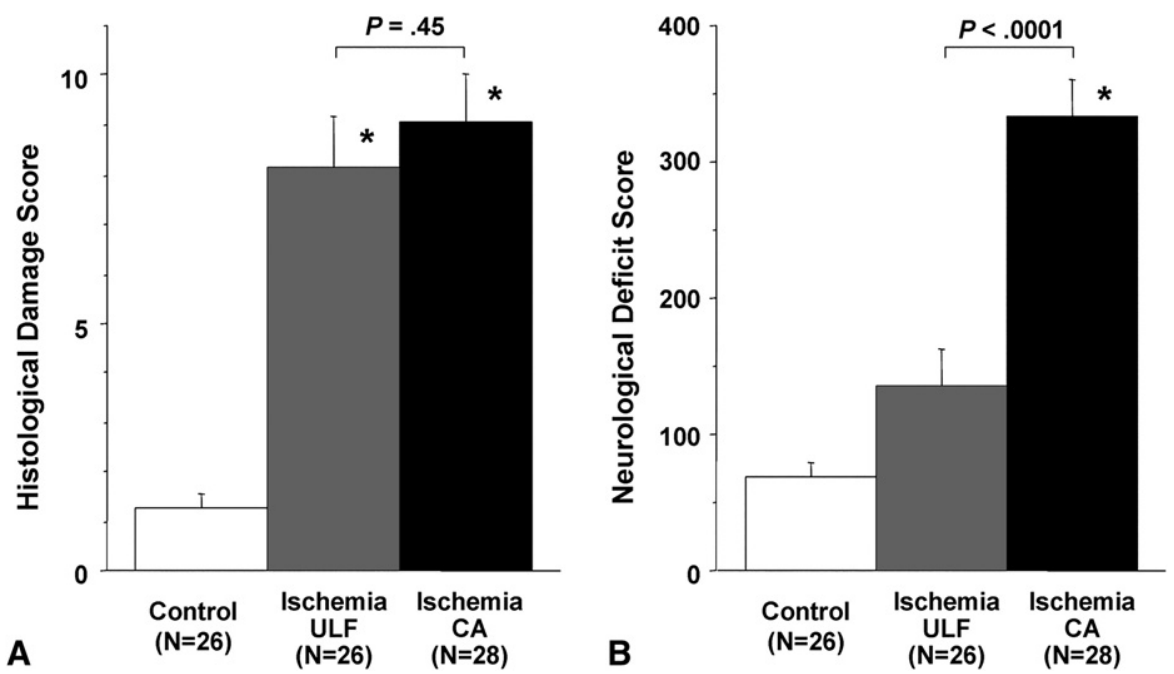

FIGURE 1. Overall histologic damage and neurologic recovery. A, Ischemia-ULF and ischemia-CA induce the same level of histologic damage. B, Neurologic recovery measured by neurologic deficit score is significantly worse in ischemia-CA compared with ischemia-ULF. Data are shown as standard error of the mean. Two ischemia groups are compared by ANOVA with Bonferroni comparison. $* P<.01$ vs control by ANOVA with Bonferroni comparison. $U L F$, Ultra-low flow bypass; $C A$, circulatory arrest; $A N O V A$, analysis of variance.

effects of aprotinin dose and/or bypass condition. Repeated-measures ANOVA were used to evaluate changes over time and to compare rates of change between the groups. One-way ANOVA with Bonferroni comparisons was used to detect differences in histologic damage, NDS, and OPC between experimental conditions. ${ }^{12}$ The Pearson correlation coefficient $(r)$ was used as a measure of linear association between TOI, NDS, OPC, and histologic damage. The odds ratio and corresponding 95\% confidence intervals for each statistically significant variable were calculated on the basis of the estimated coefficients obtained from the logistic model. In addition, FCD, adherent leukocyte numbers, and TOI were tested as possible biomarkers of neuronal damage using at least 1 point for frontal and parietal cortex, hippocampus, and caudate nucleus and more than 1 point for Purkinje cells using receiver operating characteristic curve analysis to identify optimal cutoff values and area under the curve to measure predictive accuracy of FCD and adherent leukocyte numbers and TOI in differentiating presence or absence of damage. ${ }^{13}$ For significant area under the curve values, logistic regression was applied to model the probability of damage based on TOI and FCD after 5 minutes of rewarming and mean adherent leukocyte numbers in the postbypass period. Statistical analysis was performed using SAS software (version 9.2; SAS Institute, Inc, Cary, NC), and 95\% confidence intervals were constructed, where appropriate, to provide an estimate of precision.

\section{RESULTS}

\section{Experimental Conditions}

There were no differences among the 3 groups in experimental conditions (Table E1). Each animal was given 1 of 4 doses of aprotinin. Among the groups there was no difference of the aprotinin dose (Table E1), and aprotinin did not influence histologic score $(\mathrm{F}=.70, P=.53)$.

\section{Overall Histologic Damage}

There were significant differences in total histologic damage score among groups relative to control, but ischemia-ULF and ischemia-CA induced the same level of histologic damage (Figure 1, $A$ ).
To investigate the relation between the cerebral microcirculation and overall histologic damage, we dichotomized moderate injury and severe injury at a total score 5 . There were significant differences in FCD at 5 minutes after rewarming (Figure 2, $A$ ) and in the number of adherent leukocytes after CPB (Figure 2, B). During the early postischemic period, animals with severe injury had significantly reduced FCD compared with moderate injury $(\mathrm{F}=12.9, P<.001)$, whereas the number of adherent leukocytes was not different between injury groups $(\mathrm{F}=0.04, P=.84)$. The number of adherent leukocytes in animals with moderate injury was significantly decreased during the postbypass period; on the other hand, the number in animals with severe injury was not changed (Figure 2, B). The change in adherent leukocyte numbers during the postbypass period was significantly different between moderate injury and severe injury $(\mathrm{F}=15.1, P<.001)$. By multivariate logistic regression, FCD at 5 minutes after rewarming was the most significant predictor of severe injury $(P<.05)$, whereas the number of adherent leukocytes after bypass also influenced the degree of injury $(P=.06)$. Taken together, vasoconstriction in the early postischemic period and inflammation after bypass were independent predictors of severe histologic damage.

Among animals undergoing intraoperative monitoring with near-infrared spectroscopy, there were significant differences in TOI in the ischemic phase and early postischemic phase between animals with moderate injury and severe injury (Figure 2,C). Animals with severe injury had a significantly reduced TOI during the ischemic period $(\mathrm{F}=247.7$, $P<.0001)$ and early postischemic period $(\mathrm{F}=19.1$, $P<.0001)$ compared with animals with moderate injury but not during the late postbypass period $(\mathrm{F}=0.06$, $P=0.81)$. By multivariate logistic regression, TOI 

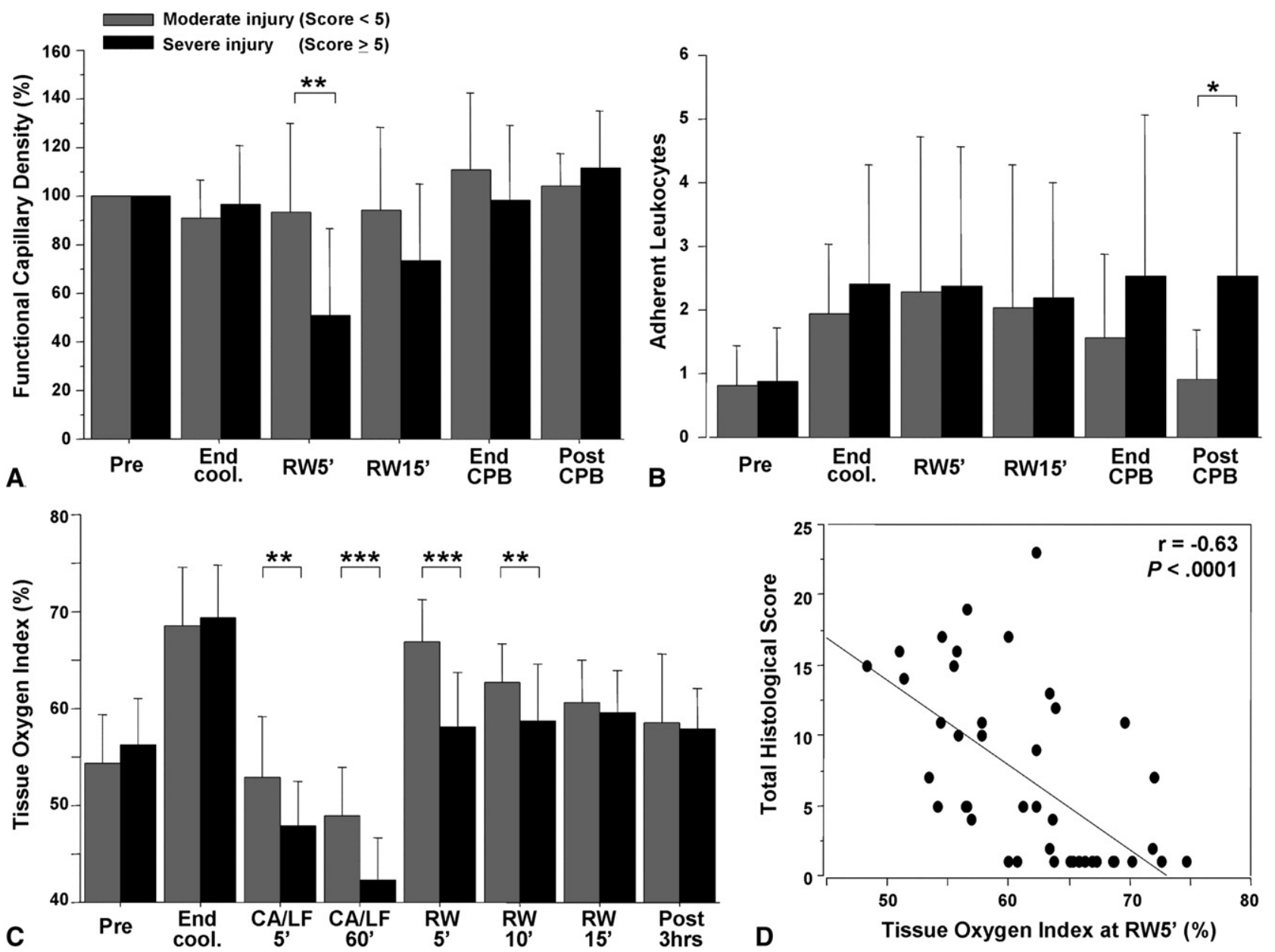

FIGURE 2. Biomarker of severe histologic damage. A, Animals with severe injury have significantly reduced recovery of functional capillary density in the early postischemic phase. B, The number of adherent leukocytes in animals with moderate injury is decreased after CPB; on the other hand, the number in animals with severe injury is not changed. C, Reduced tissue oxygen index during the ischemic phase and early postischemic phase is a significant predictor of severe injury. $\mathrm{D}$, Tissue oxygen index during rewarming is significantly associated with total histologic score. $R W$, Rewarming; $C P B$, cardiopulmonary bypass; $C A / L F$, circulatory arrest or ultra-low flow bypass; $* P<.05 ; * * P<.01 ; * * P<.001$ by unpaired Student $t$ test.

at 5 minutes after rewarming was the most powerful predictor among intraoperative monitoring modalities $(P<.01)$. Furthermore, the index was significantly correlated with total histologic score (Figure 2, D).

\section{Regional Neuron Damage}

Among 21 brain areas assessed, histologic damage was found to be most prominent in the cerebral cortex, caudate nucleus, hippocampus, and among Purkinje cells, whereas the amygdala, central white matter, anterior commissure, substantia nigra, pons, medulla, and cerebellar structures other than Purkinje cells had no histologic damage (Table E2). The 5 vulnerable areas had significant differences in histologic damage among the 3 bypass settings (Figure 3: frontal cortex, $P=.01$; parietal cortex $P=.001$; caudate nucleus, $P<.0001$; hippocampus, $P<.0001$; Purkinje cells, $P<.0001)$. The vulnerability of frontal and parietal cerebral cortex and Purkinje cells was not different between ische-
mia-ULF and ischemia-CA (Figure 3, $C$ and $L$ ), whereas the caudate nucleus was significantly vulnerable to ischemia-CA compared with ischemia-ULF (Figure 3, F). In contrast, the hippocampus was significantly vulnerable to ischemia-ULF compared with ischemia-CA (Figure 3, I).

Regarding the relation between regional neuronal damage and impaired cerebral microcirculation, lower recovery of FCD after ischemia FCD demonstrated a significant positive relationship with damage to the caudate nucleus (Figure 4, A). With FCD less than $75 \%$ at 5 minutes after rewarming, 14 of the 15 animals with neuronal damage were correctly classified with $93 \%$ sensitivity (Table E3). On the other hand, the damage in Purkinje cells and parietal cortex was positively correlated with inflammation after bypass assessed by adherent leukocyte numbers (Figure 4, B, and Table E4). Histologic score of Purkinje cells was significantly higher than that of other regions $(P<.05)$. TOI at 5 minutes after rewarming was the most powerful 

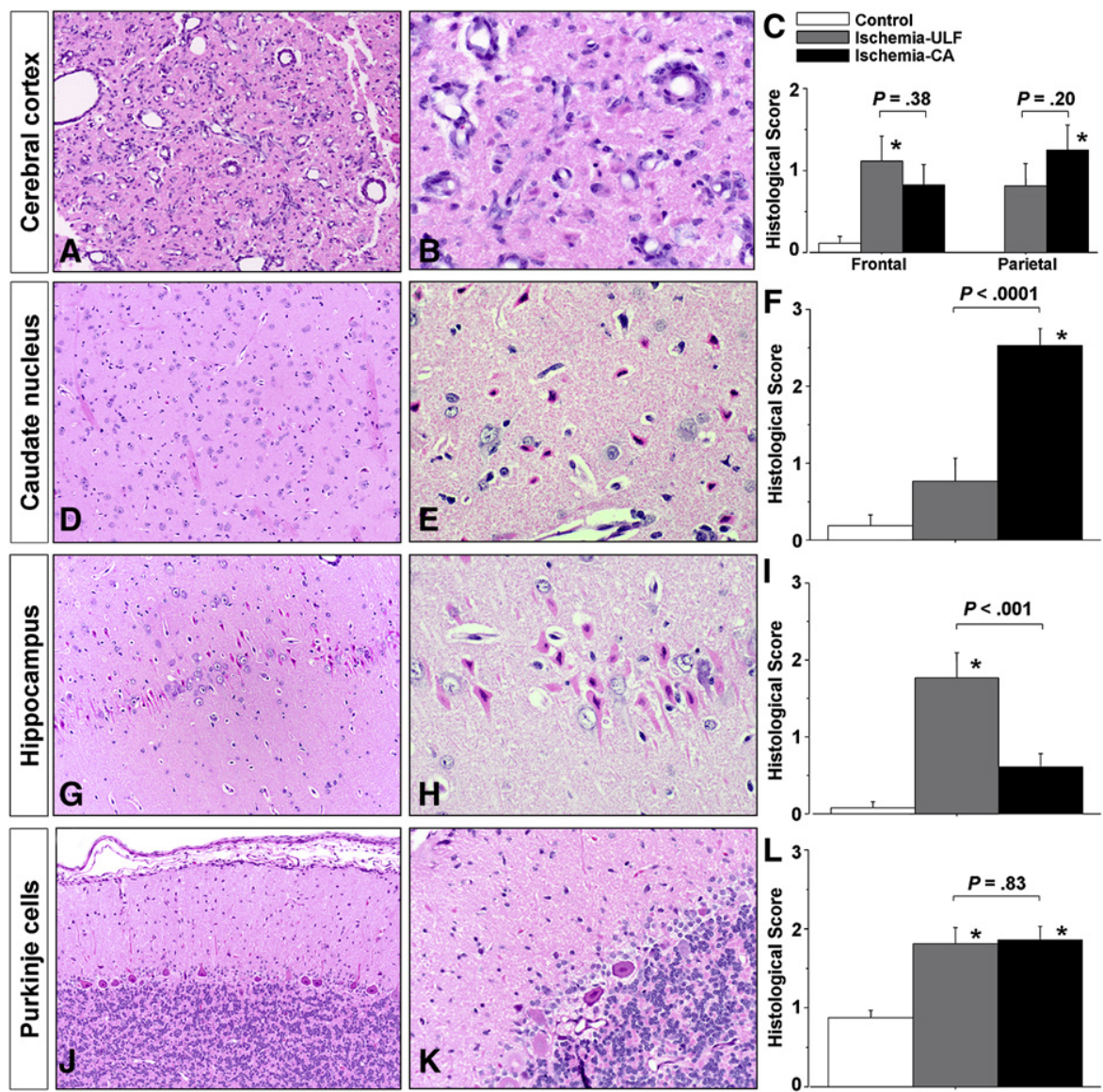

FIGURE 3. Regional neuronal damage. A-B, Cerebral cortex; all neurons necrotic (original magnifications: A, 20×; B, $60 \times$ ). C, Cerebral cortical neuronal injury is not different between 2 ischemia groups. D, Majority of caudate nucleus neurons ischemic (original magnification $20 \times$ ). E, All caudate nucleus neurons ischemic (original magnification $60 \times$ ). F, The caudate nucleus is vulnerable to ischemia-CA compared with ischemia-ULF. G-H, All hippocampus pyramidal cells ischemic (original magnifications: A, 20×; B, 60×). I, Hippocampus is vulnerable to ischemia-ULF compared with ischemia-CA. J-K, Majority of cerebellar Purkinje cells ischemic (original magnifications: A, 20×; B, 60×). L, Purkinje cell damage is not different between 2 ischemia groups. Data are shown as standard error of the mean. Two ischemia groups are compared by ANOVA with Bonferroni comparison. ${ }^{*} P<.01$ versus control by ANOVA with Bonferroni comparison.

intraoperative predictor of overall histologic damage, with the ability to accurately differentiate regional damage among all different areas (Figure 4,C). Using a median TOI at 5 minutes after rewarming of $64 \%$ based on all animals, the sensitivity was $88 \%$ for frontal cortex, $100 \%$ for parietal cortex, $86 \%$ for hippocampus, $100 \%$ for caudate nucleus, and $86 \%$ for Purkinje cells (Table E5).

\section{Neurologic Recovery}

Neuologic recovery assessed by NDS and OPC was significantly different among the 3 bypass settings at all time points $(P<.01)$. Neurologic recovery in ischemia-CA was significantly worse compared with ischemia-ULF, although there was no significant discrepancy in total histologic damage between the 2 ischemia groups (Figure 1, $B$ ). Total NDS and OPC significantly correlated with neuronal damage in the caudate nucleus, but did not correlate with damage in the hippocampus (Table 1). Similarly, NDS and OPC on POD 1 correlated with histologic damage in the caudate nucleus $(P<.0001)$ but not with damage in the hippocampus. The histologic damage in Purkinje cells tended to influence both NDS and OPC (Table 1).

\section{DISCUSSION \\ Vasoconstriction and Inflammation Are Independent Predictors of Severe Neuronal Damage}

Mechanisms of insults to the developing brain caused by CPB include the generalized systemic inflammatory response caused by blood exposure to nonendothelial surfaces, as well as ischemia-reperfusion and reoxygenation injury. Our analysis demonstrates that vasoconstriction after ischemia, as well as inflammation after bypass, are independent predictors of severe neuronal damage. Our previous studies have demonstrated that the use of the $\mathrm{pH}$-stat strategy 

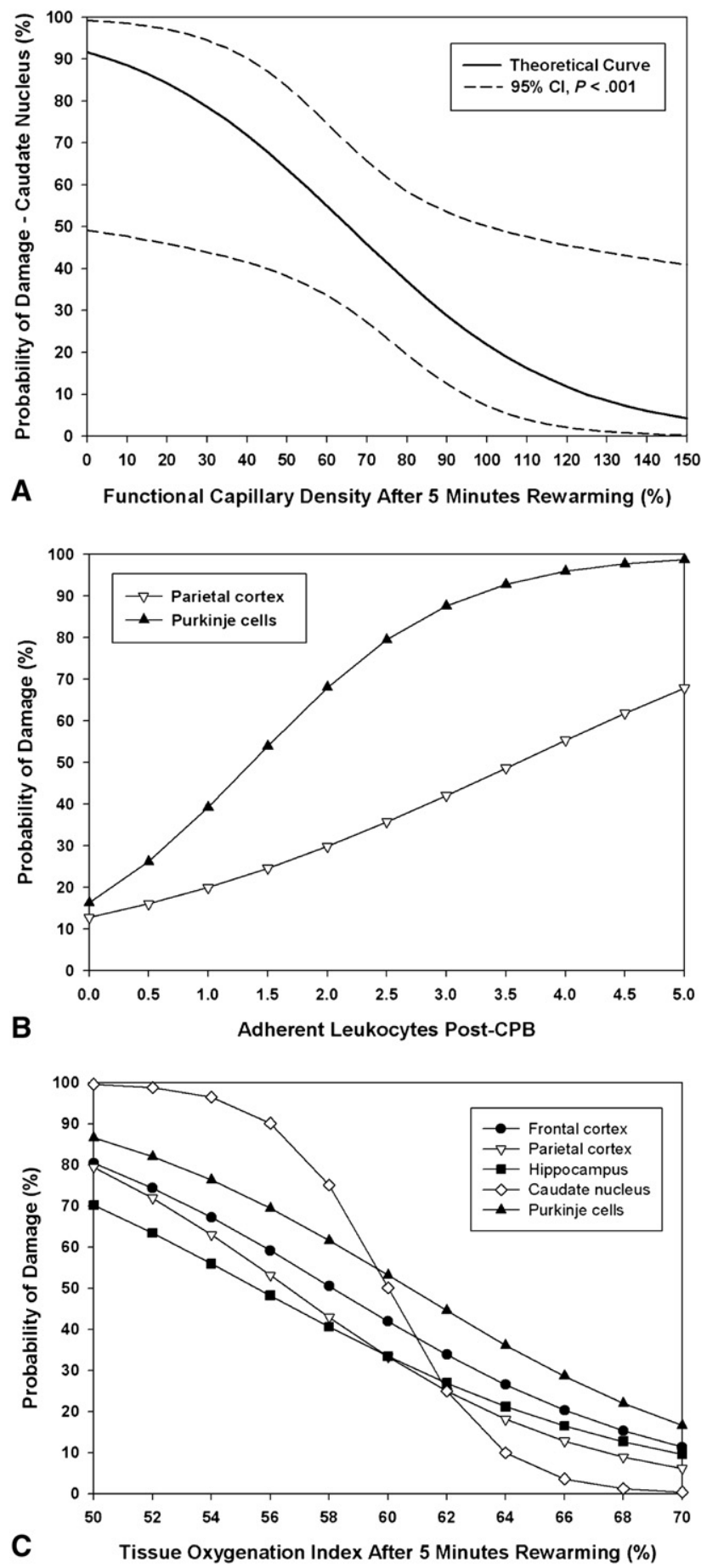

FIGURE 4. Biomarkers of regional neuronal damage. A, Functional capillary density at 5 minutes after rewarming demonstrated a significant positive relationship with damage to the caudate nucleus $(P<.01)$ by logistic regression. This was consistent with area under the receiver operating characteristic curve (area under the curve $=0.831$ ). The curve shows a decreasing probability of damage (defined by at least 1 point on histology) with higher values after rewarming. Theoretical curve and $95 \%$ confidence intervals were determined by logistic regression modeling $(\mathrm{n}=32)$. B, Postbypass number of adherent leukocytes was positively correlated with damage to parietal cortex (at least 1 point) and Purkinje cells (at least 2 points) on and high hematocrit value can protect against vasoconstriction after deep hypothermic circulatory arrest and reduce the risk of neuronal damage as determined by histologic examination. ${ }^{6}$ In addition, inflammation during low-flow bypass can be reduced by hypothermia or administration of a serine protease inhibitor such as aprotinin. ${ }^{7,11}$ The results of the current study are consistent with the previous studies and again confirm the importance of reduction of vasoconstriction and inflammation for brain protection. The results also suggest that the inflammatory response after CPB plays an important role in neuronal damage. Current strategies to reduce the systemic inflammatory syndrome during and after bypass, including hypothermia, continuous steroid infusion, and inhalation of nitric oxide, may all reduce the risk of brain injury.

\section{Neuronal Vulnerability in the Developing Brain Depends on the Mechanism of Ischemic Stress}

Previous studies have suggested that the hippocampus, Purkinje cells, striatum, cerebral cortex, and caudate nucleus are all vulnerable to $\mathrm{CPB}$-induced ischemic injury in the developing brain. ${ }^{6,7,14}$ Vulnerable regions identified in the current study are consistent with previous reports. In addition, the present study investigates the effects of different forms of ischemic stress resulting from different bypass strategies as well as the relative role of 2 major mechanisms of brain injury, that is, vasoconstriction and inflammation, in different neuronal areas.

The results of the current study demonstrate that regional neuronal injury varies according to different bypass stress and with different mechanisms. The caudate nucleus was vulnerable to ischemic stress under circulatory arrest and was significantly influenced by vasoconstriction after ischemia. This finding is no doubt secondary to vascular anatomic factors because the caudate nucleus is deeply situated in the cerebrum and most distant from penetrating vessels. A physiologic correlate of these vascular anatomic factors is the extremely low measured blood flow to the area in the human premature newborn. ${ }^{15}$ The remarkably low values measured in this area are approximately $25 \%$ of those in cortical gray matter, ${ }^{16}$ suggesting that there is a minimal margin of safety for blood flow to the area. Delayed recovery from

histology. Curves for parietal cortex $(P<.05)$ and Purkinje cells $(P<.01)$ were determined using logistic regression $(\mathrm{n}=32)$. Receiver operating characteristic analysis revealed an excellent discrimination of leukocytes in predicting Purkinje cell damage based on area under the curve (area under the curve $=0.864$ ). $\mathrm{C}$, Lower tissue oxygen index values at 5 minutes after rewarming were found to be predictive of greater neuronal damage in each region (all $P<.01$ ). Probability of damage for each region is represented by curves derived from logistic regression analysis. Damage was defined as at least 1 point for each region, except for Purkinje cells $(n=48)$, where damage was defined as 2 or more points. 
TABLE 1. Neurologic recovery and regional neuron damage $(n=80)$

\begin{tabular}{lccccc} 
& \multicolumn{2}{c}{ Total NDS } & & \multicolumn{2}{c}{ Total OPC } \\
\cline { 2 - 3 } \cline { 5 - 6 } \multicolumn{1}{c}{ Area } & $\boldsymbol{r}$ & $\boldsymbol{P}$ value & & $\boldsymbol{r}$ & $\boldsymbol{P}$ value \\
\hline Hippocampus & .03 & .80 & & .07 & .52 \\
Cerebral cortex & .26 & .02 & & .26 & .02 \\
Purkinje cells & .32 & $<.01$ & & .31 & $<.001$ \\
Caudate nucleus & .60 & $<.0001$ & & .63 & $<.0001$ \\
\hline
\end{tabular}

Pearson correlation coefficient. NDS, Neurologic deficit score; OPC, overall performance category.

vasoconstriction in the early rewarming phase would be a severe consequence of ischemic stress. Perhaps low-flow bypass is particularly protective for the caudate nucleus through maintenance of blood flow to the area and contributing to more rapid recovery from vasoconstriction.

In contrast to the caudate nucleus, the hippocampus was vulnerable to ischemic stress under low-flow bypass. The ischemia under low-flow bypass was a consequence of increased oxygen consumption secondary to raising the temperature from $25^{\circ} \mathrm{C}$ to $34{ }^{\circ} \mathrm{C}$ compared with the control group. A previous report has suggested that reduced hippocampal damage after low-flow bypass was associated with higher blood glucose levels. ${ }^{14}$ Perhaps the hippocampus is peculiarly vulnerable to a mismatch of metabolic rate and substrate uptake.

Unlike the caudate nucleus and hippocampus, different forms of energy stress did not influence Purkinje cell damage because nearly $90 \%$ of animals had histologic damage to Purkinje cells, including the control group. Damage to Purkinje cells correlated closely with inflammation after bypass. Purkinje cells are particularly sensitive to global brain ischemia. ${ }^{17}$ For example, in a rat model of cardiac arrest and resuscitation, over $60 \%$ of Purkinje cells were lost in the week after a 10 -minute arrest. ${ }^{18}$ The excitatory input from both climbing and mossy fibers and the high density of calcium channels are thought to render Purkinje cells vulnerable to excitotoxic death. ${ }^{19}$ However, more specific study is necessary to understand the cause of injury of Purkinje cells that were affected by inflammation more than vasoconstriction.

A substantial body of literature suggests that a major pathogenetic determinant for regional selectivity is the regional distribution of excitatory amino acids and amino acid neuroreceptors, regional circulatory factors, and regional metabolic factors. ${ }^{20}$ However, the relevance of these different mechanisms under bypass conditions is not well understood. To reduce the risk of CPB for the developing brain and to allow development of adjunctive protection, it is highly important to investigate cellular and molecular level events under bypass conditions. Establishing a bypass environment in vitro would be helpful to our understanding of selective vulnerability of neurons and glial cells in the developing brain in response to various bypass insults.

\section{Specific Forms of Brain Dysfunction May Not Be Apparent in Acute Neurologic Recovery after CPB}

This study demonstrates that acute neurologic recovery correlates with histologic damage in the caudate nucleus, but not with damage in the hippocampus. This result should not be surprising because the caudate nucleus plays an important role in higher motor control. Motor dysfunction is readily apparent not only in laboratory studies but also in the clinical situation. On the other hand, injury of hippocampal neurons, which are critical to memory, spatial cognition, or psychiatric disorders, may not be apparent in assessing acute neurologic recovery. In other words, bypass-induced hippocampal damage may appear as a deficit of long-term brain function such as reduced memory function or as a psychiatric disorder. Therefore, we must consider the effects of $\mathrm{CPB}$ on long-term brain function and should not rely solely on neurologic assessment of acute recovery or midterm dysfunction.

There is accumulating evidence that patients with congenital heart disease requiring surgical correction or palliation early in life are at high risk of developmental delay including academic achievement, memory index, attention, or language outcome. ${ }^{21,22}$ However, the direct impact of CPB on long-term neurodevelopmental status is still controversial. Recent neuroscience investigations have demonstrated that postnatal neurogenesis as well as gliogenesis and myelin formation play an important role in long-term neurodevelopmental status. ${ }^{23,24}$ In addition, recent postnatal stem cell research shows that dividing neural stem cells and their transit-amplifying progenitors are tightly apposed to blood vessels during both homeostasis and regeneration, and they contact the vasculature at sites that lack the blood-brain barrier, ${ }^{25}$ suggesting that neural stem cell function may be strongly influenced by bypass-induced inflammation or ischemia-reperfusion injury. Therefore, to understand the influence of neonatal and infant cardiac surgery on long-term brain function, we must investigate the effects of CPB on postnatal neurogenesis and gliogenesis originating from neural stem cells.

\section{CONCLUSIONS}

This study indicates that vasoconstriction and inflammation are independently associated with severe neuronal damage. Neuronal vulnerability in each developing brain area varies according to mechanisms of bypass-related stress. In addition, present results suggest that certain brain damage may not be apparent in assessing acute neurologic recovery after CPB. To understand the influence of CPB on long-term brain function, we must investigate the effects on postnatal neurogenesis and gliogenesis. Establishing a bypass environment in vitro would help to elucidate selective vulnerability of neurons and glial cells in developing brain to various bypass insults. Advances in our understanding of 
these areas should lead to improved brain development of patients with congenital heart disease.

\section{References}

1. Foster E, Graham TP Jr, Driscoll DJ, Reid GJ, Reiss JG, Russell IA, et al. Task force 2: special health care needs of adults with congenital heart disease. $J \mathrm{Am}$ Coll Cardiol. 2001;37:1176-83.

2. Bayer SA, Altman J, Russo RJ, Zhang X. Timetables of neurogenesis in the human brain based on experimentally determined patterns in the rat. Neurotoxicology. 1993; 14:83-144.

3. Gould E. How widespread is adult neurogenesis in mammals? Nat Rev Neurosci. 2007;8:481-8.

4. Volpe JJ. Neuronal proliferation, migration, organization, and myelination. 5th ed. Philadelphia: Saunders Elsevier; 2008.

5. McLean C, Ferriero D. Mechanisms of hypoxic-ischemic injury in the term infant. Semin Perinatol. 2004;28:425-32.

6. Sakamoto T, Zurakowski D, Duebener LF, Lidov HG, Holmes GL, Hurley RJ, et al. Interaction of temperature with hematocrit level and $\mathrm{pH}$ determines safe duration of hypothermic circulatory arrest. J Thorac Cardiovasc Surg. 2004;128: 220-32.

7. Anttila V, Hagino I, Zurakowski D, Iwata Y, Duebener L, Lidov HG, et al. Specific bypass conditions determine safe minimum flow rate. Ann Thorac Surg. 2005;80:1460-7.

8. Iwata Y, Okamura T, Ishibashi N, Zurakowski D, Lidov HG, Jonas RA. Optimal dose of aprotinin for neuroprotection and renal function in a piglet survival model. J Thorac Cardiovasc Surg. 2009;137:1521-9.

9. Ishibashi N, Iwata Y, Zurakowski D, Lidov H, Jonas R. Aprotinin protects the cerebral microcirculation during cardiopulmonary bypass. Perfusion. 2009;24: 99-105.

10. Gaber MW, Yuan H, Killmar JT, Naimark MD, Kiani MF, Merchant TE. An intravital microscopy study of radiation-induced changes in permeability and leukocyte-endothelial cell interactions in the microvessels of the rat pia mater and cremaster muscle. Brain Res Brain Res Protoc. 2004;13:1-10.

11. Anttila V, Hagino I, Iwata Y, Mettler BA, Lidov HG, Zurakowski D, et al. Aprotinin improves cerebral protection: evidence from a survival porcine model. J Thorac Cardiovasc Surg. 2006;132:948-53.
12. Cabral HJ. Multiple comparisons procedures. Circulation. 2008;117:698-701.

13. Grunkemeier GL, Jin R. Power and sample size: how many patients do I need? Ann Thorac Surg. 2007;83:1934-9.

14. Loepke AW, Golden JA, McCann JC, Kurth CD. Injury pattern of the neonatal brain after hypothermic low-flow cardiopulmonary bypass in a piglet model. Anesth Analg. 2005;101:340-8.

15. Altman DI, Powers WJ, Perlman JM, Herscovitch P, Volpe SL, Volpe JJ. Cerebra blood flow requirement for brain viability in newborn infants is lower than in adults. Ann Neurol. 1988;24:218-26.

16. Borch K, Greisen G. Blood flow distribution in the normal human preterm brain Pediatr Res. 1998;43:28-33.

17. Sarna JR, Hawkes R. Patterned Purkinje cell death in the cerebellum. Prog Neurobiol. 2003;70:473-507.

18. Brasko J, Rai P, Sabol MK, Patrikios P, Ross DT. The AMPA antagonist NBQX provides partial protection of rat cerebellar Purkinje cells after cardiac arrest and resuscitation. Brain Res. 1995;699:133-8.

19. Welsh JP, Yuen G, Placantonakis DG, Vu TQ, Haiss F, O'Hearn E, et al. Why do Purkinje cells die so easily after global brain ischemia? Aldolase C, EAAT4, and the cerebellar contribution to posthypoxic myoclonus. Adv Neurol. 2002;89: 331-59.

20. Volpe J. Brain injury and infant cardiac surgery: Overview. Boston: ButterworthHeinemann; 1995.

21. Bellinger DC, Wypij D, duPlessis AJ, Rappaport LA, Jonas RA, Wernovsky G et al. Neurodevelopmental status at eight years in children with dextrotransposition of the great arteries: the Boston Circulatory Arrest Trial. J Thorac Cardiovasc Surg. 2003;126:1385-96.

22. Wernovsky G. Current insights regarding neurological and developmental abnormalities in children and young adults with complex congenital cardiac disease Cardiol Young. 2006;16(Suppl. 1):92-104.

23. Eisch AJ, Cameron HA, Encinas JM, Meltzer LA, Ming GL, OverstreetWadiche LS. Adult neurogenesis, mental health, and mental illness: hope or hype? J Neurosci. 2008;28:11785-91.

24. Fields RD. White matter in learning, cognition and psychiatric disorders. Trends Neurosci. 2008;31:361-70.

25. Tavazoie M, Van der Veken L, Silva-Vargas V, Louissaint M, Colonna L, Zaidi B, et al. A specialized vascular niche for adult neural stem cells. Cell Stem Cell. 2008;3:279-88. 


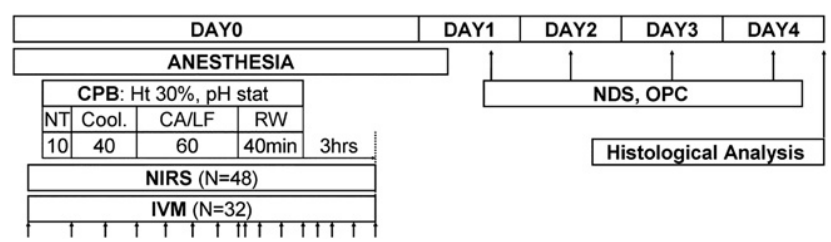

FIGURE E1. Study protocol. The pH-stat strategy was used and $30 \%$ hematocrit level was maintained in all animals during CPB. After normothermic full-flow bypass, animals underwent 40 minutes of cooling to a temperature of $25^{\circ} \mathrm{C}$ or $34^{\circ} \mathrm{C}$ according to the protocol. After cooling, circulatory arrest or ultra-low flow perfusion was initiated for 60 minutes. Animals were warmed to $37^{\circ} \mathrm{C}$ over 40 minutes of rewarming with a flow rate of $100 \mathrm{~mL} \cdot \mathrm{kg}^{-1} \cdot \mathrm{min}^{-1}$. TOI was recorded using NIRS every 10 seconds after the induction of anesthesia and for 3 hours after weaning from CPB. IVM was performed at baseline; at 10 minutes of normothermic CPB; at 20 and 40 minutes of cooling; at every 15 minutes during circulatory arrest or ultra-low flow period; 5, 15, 30, and 40 minutes of rewarming; and at 30, 60,120 , and 180 minutes after weaning from CPB. $C P B$, Cardiopulmonary bypass; $N T$, normothermia; $C A / L F$, circulatory arrest or ultra-low flow bypass; $R W$, rewarming; NIRS, near-infrared spectroscopy; IVM, intravital microscopy; $N D S$, neuronal deficit score; $O P C$, overall performance category; TOI, tissue oxygen index. 
Table E1. Experimental conditions

\begin{tabular}{|c|c|c|c|c|c|}
\hline & Control $(n=26)$ & Ischemia-ULF $(n=26)$ & Ischemia-CA $(n=28)$ & F test & $P$ value \\
\hline \multicolumn{6}{|l|}{ Temperature } \\
\hline Pre & $36.0 \pm 0.8$ & $36.0 \pm 0.5$ & $35.9 \pm 1.0$ & 0.24 & .79 \\
\hline End of CPB & $36.8 \pm 0.9$ & $37.2 \pm 0.4$ & $37.0 \pm 0.6$ & 1.45 & .24 \\
\hline $3 \mathrm{~h} \mathrm{CPB}$ & $36.7 \pm 0.6$ & $36.9 \pm 0.5$ & $36.6 \pm 0.7$ & 1.75 & .18 \\
\hline $12 \mathrm{~h} \mathrm{CPB}$ & $37.3 \pm 0.5$ & $37.2 \pm 0.5$ & $37.3 \pm 0.5$ & 0.26 & .77 \\
\hline \multicolumn{6}{|l|}{$\mathrm{pH}$} \\
\hline Pre & $7.51 \pm 0.07$ & $7.52 \pm 0.04$ & $7.52 \pm 0.03$ & 0.51 & .60 \\
\hline End of $\mathrm{CPB}$ & $7.51 \pm 0.08$ & $7.48 \pm 0.08$ & $7.47 \pm 0.10$ & 1.59 & .21 \\
\hline $3 \mathrm{~h} \mathrm{CPB}$ & $7.56 \pm 0.07$ & $7.56 \pm 0.04$ & $7.55 \pm 0.07$ & 0.11 & .89 \\
\hline 12 h CPB & $7.51 \pm 0.07$ & $7.52 \pm 0.06$ & $7.52 \pm 0.07$ & 0.01 & .99 \\
\hline \multicolumn{6}{|l|}{$\mathrm{PaO}_{2}(\mathrm{~mm} \mathrm{Hg})$} \\
\hline Pre & $74.0 \pm 13.6$ & $71.0 \pm 14.7$ & $73.4 \pm 11.3$ & 0.36 & .70 \\
\hline End of $\mathrm{CPB}$ & $514.4 \pm 62.3$ & $521.4 \pm 65.7$ & $519.5 \pm 62.4$ & 0.08 & .92 \\
\hline $3 \mathrm{~h} \mathrm{CPB}$ & $314.0 \pm 94.7$ & $317.8 \pm 78.0$ & $318.2 \pm 89.2$ & 0.02 & .98 \\
\hline $12 \mathrm{~h} \mathrm{CPB}$ & $72.1 \pm 16.5$ & $76.6 \pm 13.8$ & $75.6 \pm 16.0$ & 0.60 & .55 \\
\hline \multicolumn{6}{|l|}{$\mathrm{PaCO}_{2}(\mathrm{~mm} \mathrm{Hg})$} \\
\hline Pre & $39.7 \pm 3.7$ & $39.6 \pm 3.1$ & $39.9 \pm 2.2$ & 0.04 & .96 \\
\hline End of CPB & $39.8 \pm 6.9$ & $39.8 \pm 7.3$ & $40.1 \pm 8.6$ & 0.01 & .99 \\
\hline $3 \mathrm{~h} \mathrm{CPB}$ & $35.5 \pm 6.3$ & $35.9 \pm 4.3$ & $34.2 \pm 5.5$ & 1.01 & .35 \\
\hline 12 h CPB & $38.5 \pm 5.4$ & $37.8 \pm 5.4$ & $39.1 \pm 5.6$ & 0.39 & .68 \\
\hline \multicolumn{6}{|l|}{ Hematocrit $(\%)$} \\
\hline Pre & $29.2 \pm 3.1$ & $29.6 \pm 1.9$ & $29.2 \pm 2.6$ & 0.16 & .85 \\
\hline End of CPB & $29.9 \pm 1.9$ & $29.3 \pm 1.8$ & $29.5 \pm 1.7$ & 0.70 & .50 \\
\hline $3 \mathrm{~h} \mathrm{CPB}$ & $28.7 \pm 3.1$ & $28.1 \pm 2.7$ & $28.3 \pm 2.0$ & 0.37 & .69 \\
\hline 12 h CPB & $28.7 \pm 3.0$ & $28.4 \pm 3.4$ & $28.3 \pm 3.3$ & 0.14 & .87 \\
\hline \multicolumn{6}{|l|}{ MAP (mm Hg) } \\
\hline Pre & $69.6 \pm 15.0$ & $73.8 \pm 13.4$ & $74.7 \pm 11.6$ & 1.10 & .34 \\
\hline End of $\mathrm{CPB}$ & $88.2 \pm 14.0$ & $88.4 \pm 17.7$ & $90.4 \pm 13.8$ & 0.18 & .84 \\
\hline $3 \mathrm{~h} \mathrm{CPB}$ & $81.3 \pm 12.9$ & $80.9 \pm 12.0$ & $87.4 \pm 13.0$ & 2.30 & .11 \\
\hline $12 \mathrm{~h} \mathrm{CPB}$ & $89.0 \pm 15.0$ & $90.0 \pm 12.6$ & $90.9 \pm 14.0$ & 0.14 & .87 \\
\hline \multicolumn{6}{|l|}{ AP dose (n) } \\
\hline No AP & 7 & 6 & 9 & & .98 \\
\hline Low & 6 & 8 & 6 & & \\
\hline Full & 6 & 6 & 7 & & \\
\hline Double Full & 7 & 6 & 6 & & \\
\hline
\end{tabular}

ANOVA with $\mathrm{F}$ test and $\chi^{2}$ test. $U L F$, Ultra-low flow bypass; $C A$, circulatory arrest; $C P B$, cardiopulmonary bypass; $\mathrm{PaO}_{2}$, arterial oxygen tension; Paco 2 , arterial carbon dioxide tension; $M A P$, mean arterial pressure; $A P$, aprotinin. 
Table E2. Regional neuron damage $(\mathbf{n}=\mathbf{8 0})$

\begin{tabular}{lc}
\hline \multicolumn{1}{c}{ Area } & $\mathbf{n}(\%)$ \\
\hline Cerebral cortex & \\
Frontal cortex & $22(28)$ \\
Parietal cortex & $22(28)$ \\
Occipital cortex & $18(19)$ \\
Temporal cortex & $6(8)$ \\
Basal ganglia & \\
Caudate nucleus & $32(40)$ \\
Putamen & $14(18)$ \\
Limbic structure & \\
Hippocampus & $26(33)$ \\
Dendate gyrus & $7(9)$ \\
Amygdala & $0(0)$ \\
Central white matter & $0(0)$ \\
Anterior commissure & $0(0)$ \\
Corpus callosum & $1(1)$ \\
Thalamus & $6(8)$ \\
Midbrain & $2(3)$ \\
Substania nigra & $0(0)$ \\
Pons & $0(0)$ \\
Medulla & $0(0)$ \\
Cerebellum & \\
Deep nucleus & $0(0)$ \\
Granule cells & $0(0)$ \\
Purkinje cells & $71(89)$ \\
[score $>$ 1] & {$[36(45)]$} \\
Anterior horn cells & $0(0)$ \\
\hline
\end{tabular}

Table E4. Adherent Leukocytes Post CPB as Biomarker of Regional Damage $(\mathbf{n}=32)$

\begin{tabular}{|c|c|c|c|}
\hline Region & AUC & $95 \% \mathrm{CI}$ & $P$ value \\
\hline Frontal cortex & 0.613 & $0.344-0.882$ & .481 \\
\hline Parietal cortex & 0.800 & $0.606-0.994$ & $.042 *$ \\
\hline Hippocampus & 0.601 & $0.363-0.839$ & .412 \\
\hline Caudate nucleus & 0.587 & $0.356-0.817$ & .463 \\
\hline Purkinje cells $>1$ & 0.864 & $0.695-0.999$ & $.002 *$ \\
\hline
\end{tabular}

Table E3. FCD after 5 hours of rewarming as biomarker of regional damage $(\mathbf{n}=32)$

\begin{tabular}{lccc}
\hline \multicolumn{1}{c}{ Region } & AUC & $\mathbf{9 5} \%$ CI & $\boldsymbol{P}$ value \\
\hline Frontal cortex & 0.741 & $0.489-0.992$ & .092 \\
Parietal cortex & 0.651 & $0.459-0.943$ & .207 \\
Hippocampus & 0.547 & $0.335-0.758$ & .108 \\
Caudate nucleus & 0.831 & $0.675-0.987$ & $<.001^{*}$ \\
Purkinje cells $>1$ & 0.541 & $0.329-0.753$ & .692 \\
\hline
\end{tabular}

$F C D$, Functional capillary density; $A U C$, area under the curve; $C I$, confidence interval. *Statistically significant.

Table E5. TOI as biomarker of regional damage $(n=48)$

\begin{tabular}{llcr}
\hline \multicolumn{1}{c}{ Region } & AUC & $\mathbf{9 5} \%$ CI & $\boldsymbol{P}$ value \\
\hline Frontal cortex & 0.775 & $0.629-0.919$ & $.002^{*}$ \\
Parietal cortex & 0.812 & $0.693-0.931$ & $<.001^{*}$ \\
Hippocampus & 0.753 & $0.587-0.919$ & $.006^{*}$ \\
Caudate nucleus & 0.956 & $0.900-0.999$ & $<.001 *$ \\
Purkinje cells $>1$ & 0.780 & $0.640-0.920$ & $<.001 *$ \\
\hline Regional damage is defined as at least one point on histopathology for frontal and pa- \\
rietal cortex, hippocampus, and caudate nucleus and two or more points for Purkinje \\
cells in cerebellum. TOI, Tissue oxygen index; AUC, area under the curve; $C I$, confi- \\
dence interval. *Statistically significant.
\end{tabular}

1415.e3 The Journal of Thoracic and Cardiovascular Surgery • December 2010 